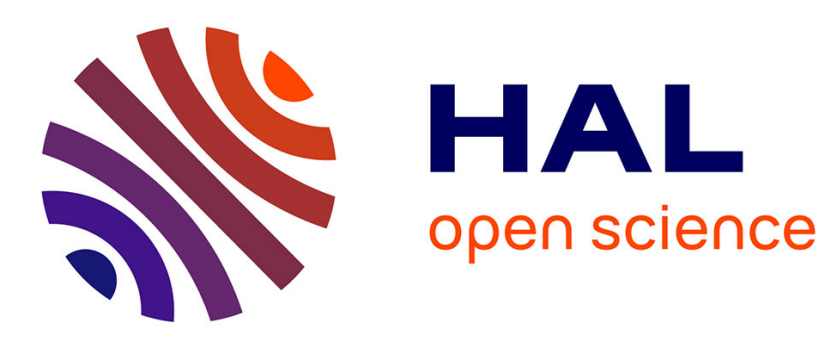

\title{
Nonlinear couplings in a gear-shaft-bearing system
}

Sébastien Baguet, Guillaume Jacquenot

\section{To cite this version:}

Sébastien Baguet, Guillaume Jacquenot. Nonlinear couplings in a gear-shaft-bearing system. Mechanism and Machine Theory, 2010, 45 (12), pp.1777-1796. 10.1016/j.mechmachtheory.2010.08.009 . hal-00633140

\section{HAL Id: hal-00633140 \\ https://hal.science/hal-00633140}

Submitted on 18 Sep 2014

HAL is a multi-disciplinary open access archive for the deposit and dissemination of scientific research documents, whether they are published or not. The documents may come from teaching and research institutions in France or abroad, or from public or private research centers.
L'archive ouverte pluridisciplinaire HAL, est destinée au dépôt et à la diffusion de documents scientifiques de niveau recherche, publiés ou non, émanant des établissements d'enseignement et de recherche français ou étrangers, des laboratoires publics ou privés. 


\title{
Nonlinear couplings in a gear-shaft-bearing system
}

\author{
S. Baguet ${ }^{*, a}$, G. Jacquenot ${ }^{\mathrm{a}}$ \\ ${ }^{a}$ Université de Lyon, CNRS \\ INSA-Lyon, LaMCoS UMR5259, F-69621, Villeurbanne, France
}

\begin{abstract}
The present work contributes to the analysis of the interactions between gears, shafts and hydrodynamic journal bearings in geared drives. In contrast to the majority of the models in the literature, the time-varying properties and nonlinearities of gears and bearings are introduced in the simulations. A finite element model is used for the shafts, and a specific gear element is used to account for nonlinear time-varying mesh stiffness as well as tooth shape deviations. The nonlinear hydrodynamic forces are computed with the Reynolds equation for finite-length journal bearings. An iterative Newmark scheme is used to solve simultaneously the motion equations for the shafts, the contact problem for the gears, and the fluid forces in the bearings. The resulting algorithm is applied to a single stage geared system with two shafts, four bearings, a pinion and a gear. Gear-bearing dynamic interactions are demonstrated through the analysis of dynamic gear loads, dynamic bearing loads and bearing displacements. The efficiency of the proposed numerical procedure, the interest of nonlinear models for hydrodynamic bearings and the influence of several parameters ruling the gear assembly are also discussed.
\end{abstract}

Key words: rotor, gears, hydrodynamic journal bearing, couplings, nonlinear dynamics, finite elements. 


\section{Nomenclature}

$C$ bearing radial clearance $(m)$

$D$ bearing diameter $(m)$

$F_{b}$ fluid film forces in local frame $(N)$

$\bar{F}_{b}$ dimensionless fluid film forces in local frame, $\bar{F}_{b}=F_{b} /\left[6 \mu \omega R^{2}(R / C)^{2}\right]$

$h$ fluid film thickness $(m)$

$\bar{h}$ dimensionless fluid film thickness, $\bar{h}=h / C$

$L$ bearing length $(m)$

$\mathbf{M}, \mathbf{C}, \mathbf{K}$ global mass ,damping and stiffness matrices of the gear-bearing system

$O$ bearing center

$O^{\prime}$ journal center

$p$ fluid film pressure $(\mathrm{Pa})$

$\bar{p}$ dimensionless fluid film pressure, $\bar{p}=p /\left[6 \mu \omega(R / C)^{2}\right]$

$R$ bearing radius $(m), R=D / 2$

$\vec{s}, \vec{t}, \vec{z}$ global frame related to the geared system

$T$ input torque (N.m)

$W$ static load $(N)$

$\vec{x}, \vec{y}$ local frame related to the journal bearing

$x_{0}, y_{0}$ static displacement of the journal center in local frame $(\mathrm{m})$

$x, y$ time-dependent displacement of the journal center in local frame $(m)$

$\dot{x}, \dot{y}$ velocities of the journal center in local frame $(\mathrm{m} / \mathrm{s})$

$\bar{x}, \bar{y}$ dimensionless displacement of the journal center in local frame, $\bar{x}=x / C, \bar{y}=y / C$

$\dot{\bar{x}} \dot{\bar{y}}$ dimensionless velocities of the journal center in local frame, $\dot{\bar{x}}=\dot{x} / C \omega, \dot{\bar{y}}=\dot{y} / C \omega$

$\mathbf{X}, \dot{\mathbf{X}}, \ddot{\mathbf{X}}$ degree-of-freedom, velocity and acceleration vectors in global frame $(m)$

$Z$ gear number of teeth

$\alpha$ gear pressure angle $\left({ }^{\circ}\right)$

$\beta$ gear helix angle $\left(^{\circ}\right)$

$\mu$ fluid film dynamic viscosity (Pa.s)

$\omega$ angular speed of rotation $(\mathrm{rad} / \mathrm{s})$

$\theta, \xi$ circumferential and axial coordinates in local frame 


\section{Introduction}

Even though there have been numerous studies on the topic, the dynamic response of geared rotor-bearing systems is still a matter of considerable concern in terms of noise and vibration. In the dynamic regime, meshing forces may combine amplified and high-frequency loadings, causing shocks between the teeth and radiating noise. This dynamic excitation is also transmitted to the supporting structure through the shafts and the bearings, which in general is not desirable. Therefore, it is essential to accurately represent the different components of the gear-bearing system, so that the relevant parameters ruling its dynamic behavior may be identified.

For high-speed applications, journal bearings are recognized as interesting technological solutions since they provide significant stiffness and damping for reduced noise levels compared with rolling element bearings. The literature on journal bearings comprises numerous contributions, only a few of which can be cited here $[1,2,3,4,5]$ and it is now accepted that, for most practical cases, the theoretical foundations are firmly established allowing accurate predictions of bearing performance.

On the other hand, the simulation of gear dynamics has yielded a vast literature with the majority of the gear models based upon lumped parameter representations combining rigid gears, discrete elastic and dissipative elements $[6,7,8]$, or, more recently, on combinations of shaft finite elements and elastic foundations [9]. Forcing terms are often derived from transmission errors (Gregory et al. [8], Munro [10], Özgüven and Houser [11]) and/or the contact conditions between the active flanks [12]. Nonlinear features in spur gearing such as backlash and shocks on tooth flanks have been analyzed by Kahraman and Singh [13], Kahraman and Blankenship [14], Parker et al. [15]. Papers by Özgüven and Houser [16] and Wang et al. [17] provide a comprehensive review of these models and a survey on the dynamics of geared systems.

Dynamic models combining gears with flexible shafts and bearings have been investigated by many authors. However, the models in the literature are of varying complexity and most of them do not include the time-varying properties and nonlinearities of bearings and gears in the simulations. In the earlier models of Neriya et al. [18] and Kahraman et al. [19], a finite element representation was used for the shafts, although a linearized bearing model with spring and damping coefficients and simplified lumped gear models were considered. Choy et al. [20] studied the coupling between a geared rotor-bearing system and a finite element gearbox structure. They used a linearized bearing model and periodic nonlinear mesh stiffness. Nonlinear features of gears, such as backlash, were considered by Özgüven [21] in conjunction with a lumped shaft-bearing model. Kahraman and Singh [22] developed a similar model and added the clearance nonlinearities of the bearings. More recently, Baud and Velex [23] and Maliha et al. [24] investigated the dynamics of gear-shaft-bearing systems using a nonlinear gear model, finite elements for the shafts, and a classical linearized 8-coefficient bearing model. The nonlinear properties of hydrodynamic bearings were incorporated by Kishor and Gupta [25] in a lumped shaft-bearing model with a simplified gear model. A nonlinear analytic approximation for long bearings was used. Chen et al. [26] employed the nonlinear analytic short bearing theory with a finite-length correction together with a gear model with constant stiffness and damping parameters and no backlash. A study combining both gear and bearing nonlinearities with finite elements for the shafts was carried out by Theodossiades and Natsiavas [27]. In this work, both the gear meshing stiffness and the static transmission error were assumed to be periodic functions of the driving gear rotation, backlash was considered, and bearing forces were evaluated by means of the analytic finite-length impedance method. Another model was proposed by Baguet and Velex [28], which includes a distributed meshing formulation and nonlinear bearing forces obtained by the short bearing theory.

The present work is based on the model presented in [28] and extends it to helical gears and finite-length hydrodynamic bearings. To this end, the equations of motion, the normal contact problem between mating flanks and the Reynolds equation for finite-length bearings are solved simultaneously by combining a time-step integration scheme, a Newton-Raphson procedure and a normal contact algorithm. The resulting algorithm is applied to a single stage geared system with two shafts, four bearings, a pinion and a gear while taking mass unbalance, eccentricity and meshing excitations into account. Gear-bearing dynamic interactions are demonstrated through the analysis of dynamic gear loads, dynamic bearing loads and bearing displacements. The efficiency of the proposed model and numerical procedure, and the interest of nonlinear models for hydrodynamic bearings are also discussed. Finally, parametric studies are performed for several design and working parameters in order to quantify their influence on the overall behavior of the gear-bearing system. 




Figure 1: (a) Sketch of the geared system (b) base plane and associated local frame.

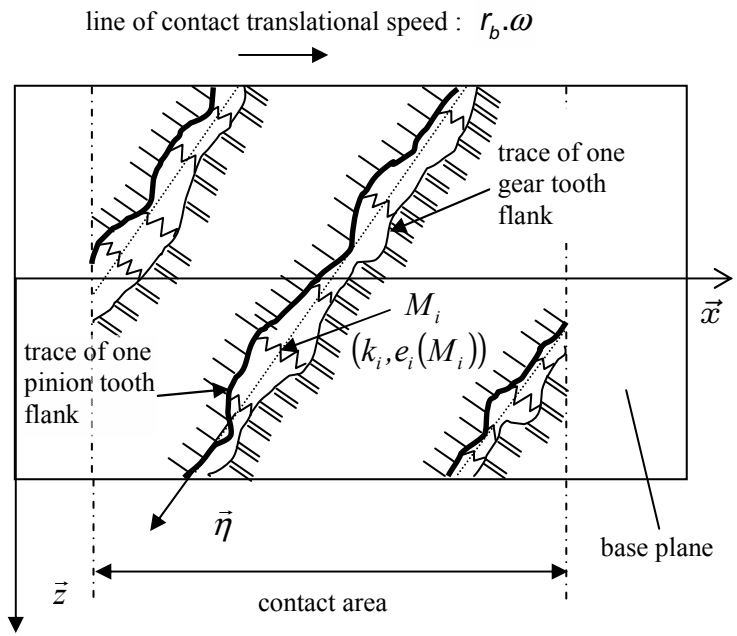

Figure 2: Model of mesh elasticity and tooth shape deviations.

\section{Description of the model}

\subsection{Shaft-gear model}

The dynamic model of single stage transmissions (Fig. 1) is based on the developments of Velex and Maatar [12] and Ajmi and Velex [9]. Shafts are modeled by classical two-node finite elements with 6 degrees of freedom per node for bending (Timoschenko's beam), torsion and axial displacements. A pinion-gear pair is represented by two 2-node shaft elements connected by a series of lumped stiffnesses distributed along the contact lines in the base plane (Figs. 1 and 2). The associated gear mesh stiffness function is initialized using the equations of Weber and Banaschek [29] in order to account for contact, tooth deflection and foundation flexibility. An elemental mesh stiffness and an equivalent normal shape deviation are associated with every potential point of contact to simulate tooth flank traces and their evolutions with time. Based upon rigid-body kinematics, the lines of contact are translated and all the relevant parameters (stiffness and deviations) are re-calculated at each time step of the meshing process. It is assumed that the contacts between mating flanks are line contacts within the theoretical base plane and that tooth friction forces can be neglected when compared with normal forces. The normal contact condition at every potential point of contact on the tooth flanks is directly included in the mesh stiffness formulation by canceling the elemental stiffness when the corresponding deflection is negative or nil. The proposed formulation leads to time-varying nonlinear mesh stiffness matrices and forcing terms, the latter accounting for tooth shape deviations and mounting errors $[9,23,12]$. The pinion-gear mass matrix is classical since second order terms and gyroscopic components are neglected. 

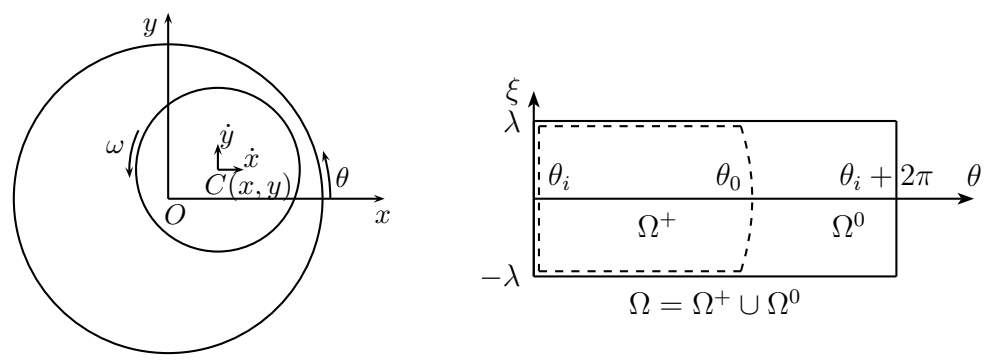

Figure 3: A journal bearing and its planar expansion in local coordinates.

\subsection{Hydrodynamic journal bearing model}

\subsubsection{Governing equations}

Figure 3 gives a schematic view of a journal bearing consisting of a fixed journal of radius $R$, length $L$ and of a rotating shaft of radius $R_{s}$, with $C=R-R_{s}$ being the radial clearance. At constant speed $\omega$ and under a constant load $W$ (static conditions), the shaft center $O^{\prime}$ keeps a fixed position in the bearing defined by the local coordinates $\left(x_{0}, y_{0}\right)$ whereas for dynamic conditions it follows an orbit within the journal clearance characterized by time-dependent coordinates $(x, y)$. Denoting the dynamic variation of position $(\Delta x, \Delta y)$ due to the dynamic variation of the applied load, the displacement of the shaft center is given by

$$
\overrightarrow{O O^{\prime}}=x \vec{x}+y \vec{y}=\left(x_{0}+\Delta x\right) \vec{x}+\left(y_{0}+\Delta y\right) \vec{y}
$$

Assuming an isothermal, laminar flow of an iso-viscous incompressible fluid, the dimensionless pressure distribution $\bar{p}$ of the lubricant is governed by the dimensionless Reynolds equation [2]

$$
\begin{aligned}
\frac{\partial}{\partial \theta}\left(\bar{h}^{3} \frac{\partial \bar{p}}{\partial \theta}\right)+\frac{\partial}{\partial \xi}\left(\bar{h}^{3} \frac{\partial \bar{p}}{\partial \xi}\right) & =-f & & \text { in } \Omega^{+}=\left[\theta_{i}, \theta_{0}\right] \times[-\lambda, \lambda] \\
\bar{p}(\theta, \xi) & \geqslant 0 & & \text { on } \Omega \\
\bar{p}(\theta, \xi) & =0 & & \text { on } \partial \Omega
\end{aligned}
$$

where $\Omega$ is the fluid film region, with boundary $\partial \Omega$ (Fig. 3), and

$$
\begin{aligned}
& \bar{h}=1-\bar{x} \cos \theta-\bar{y} \sin \theta \\
& f=(\bar{y}+2 \dot{\bar{x}}) \cos \theta+(2 \dot{\bar{y}}-\bar{x}) \sin \theta
\end{aligned}
$$

Customary Swift-Steiber (Reynolds) boundary conditions are used to ensure the transition from the pressurized zone $\left(\Omega^{+}\right)$to the cavitated zone $\left(\Omega^{0}\right)$

$$
\bar{p}(\theta, \xi)=\frac{\partial \bar{p}}{\partial \theta}(\theta, \xi)=0 \quad \text { at } \theta=\theta_{0}
$$

where $\theta_{0}$ is the end of the hydrodynamic film. Feeding grooves have been positioned so that they do not interfere with the pressure field. The bar indicates dimensionless variables, with the dimensional scale given in Nomenclature. Hence $\bar{x}, \bar{y}$ are the dimensionless displacements of the shaft center, $\dot{\bar{x}}, \dot{\bar{y}}$ are the corresponding velocities, and $\bar{h}$ is the dimensionless film thickness. The two dimensionless components of fluid forces $\overline{\mathbf{F}}_{\mathbf{b}}$ in frame $(\vec{x}, \vec{y})$ are obtained by integrating the fluid pressure over the bearing and give

$$
\left\{\overline{\mathbf{F}}_{\mathbf{b}}\right\}_{(\vec{x}, \vec{y})}=\left\{\begin{array}{c}
\bar{F}_{b x}(\bar{x}, \bar{y}, \dot{\bar{x}}, \dot{\bar{y}}) \\
\bar{F}_{b y}(\bar{x}, \bar{y}, \overline{\bar{x}}, \dot{\bar{y}})
\end{array}\right\}=\left\{\begin{array}{c}
-\iint_{\Omega} \bar{p}(\theta, \xi) \cos \theta d \theta d \xi \\
-\iint_{\Omega} \bar{p}(\theta, \xi) \sin \theta d \theta d \xi
\end{array}\right\}
$$

Physical fluid forces $\mathbf{F}_{\mathbf{b}}$ can then be evaluated and expressed in the global frame $(\vec{s}, \vec{t}, \vec{z})$ by a classical change of basis. 


\subsubsection{Numerical calculation of hydrodynamic forces (hybrid method)}

Analytical solutions for Eq. (2) exist only for short $(L / D<1 / 8)$ and long bearings $(L / D>4)$, whereas numerical procedures must be used for finite length bearings [5]. For finite length bearings, the easiest way to solve the Reynolds equation numerically is to use the finite difference method (Klit and Lund [31]). However, the complexity of this method is $O\left(n^{2}\right)$, where $n$ is the total number of points on the $2 D$ mesh of the bearing. Multigrid methods (Venner and Lubrecht [32]) using different mesh-grids to reduce the error on the finest grid as fast as possible, allow solving this problem with a complexity of order $O(n \log n)$. This method was successfully implemented in the present study, and computational time reduction was noticeable. However, the nonlinear dynamic simulation of a gear-bearing assembly requires the evaluation of a large number of hydrodynamic fluid forces, and even the multigrid method is not fast enough to perform such a simulation within a reasonable time (see section 4.2.1).

Zheng et al. [30] recently proposed a method to efficiently compute fluid forces and Jacobian matrices. The method is based on the theory of variational inequality with a Reynolds boundary condition. The Reynolds equation Eq. (2) is first transformed into a variational inequality, then solved using a variable separation: the pressure field is expressed as a product of an analytic function along the $\xi$-axis and a numerical function $a(\theta)$ along the $\theta$-axis

$$
\bar{p}(\theta, \xi)=[\cosh (k \lambda)-\cosh (k \xi)] a(\theta)
$$

where $k$ is an iterative parameter. The discretization of function $a(\theta)$ allows solving the problem numerically

$$
\begin{aligned}
a(\theta) & =\mathbf{a}^{T} \mathbf{l}(\theta) \\
\mathbf{a} & =\left[a_{1}, a_{2}, \ldots, a_{n}\right]^{T} \\
\mathbf{l}(\theta) & =\left[l_{1}(\theta), l_{2}(\theta), \ldots, l_{n}(\theta)\right]^{T}
\end{aligned}
$$

where $\mathbf{a}$ is the finite element vector of unknowns, $\mathbf{l}(\theta)$ is composed of $n$ global functions of piecewise interpolation. The resulting symmetric tridiagonal linear system provides the parameter $k$ and the vector a. Depending on the required accuracy, only 3 or 4 iterations are usually needed to adjust $k$. Moreover, the Reynolds boundary conditions are automatically satisfied, and the Jacobian matrices of fluid forces can be obtained with a few costless additional operations. In comparison with other methods, numerical differentiation is not needed, resulting in very considerable time saving (computation times are compared in section 4.2.1). This method is also an excellent compromise between accuracy and computational cost. Comparison with the multigrid method shows slight differences in the pressure field only in the transition zone between the pressurized domain and the cavitation domain. The overall relative difference on the resulting load is less than $10^{-4}$. In the following, because of the hybrid analytic-numerical separation of variables, this method will be referred to as the hybrid method.

\subsubsection{Static solution}

The bearing forces $\mathbf{F}_{\mathbf{b} \mathbf{0}}$ for static conditions can be deduced from Eqs. (2) and (3) by setting the velocities $\dot{\bar{x}}$ and $\dot{\bar{y}}$ to zero. They depend only on $\left(x_{0}, y_{0}\right)$ and have to equilibrate the external force $\mathbf{W}_{\mathbf{0}}$ imposed by the input torque and transmitted to the bearings by the pinion and the gear, i.e.,

$$
\mathbf{F}_{\mathbf{b} \mathbf{0}}\left(x_{0}, y_{0}\right)=\mathbf{W}_{\mathbf{0}}
$$

This nonlinear equation is solved by an iterative Regula-Falsi method and provides the initial static position $\left(x_{0}, y_{0}\right)$ of the center of the shaft in the bearing. In turn, this eccentricity of the shafts in the journals slightly modifies the pinion-gear center distance, thus the gear mesh stiffness function and excitations must be re-evaluated. This static position $\left(x_{0}, y_{0}\right)$ is used to initialize the transient dynamic problem.

\section{Dynamic behavior of the gear-bearing assembly}

\subsection{Equations of motion}

The assembly of all the elemental matrices and forcing term vectors leads to the following system of equations in the frame $(\vec{s}, \vec{t}, \vec{z})$ relative to the structure

$$
[\mathbf{M}]\{\ddot{\mathbf{X}}\}+[\mathbf{C}]\{\dot{\mathbf{X}}\}+[\mathbf{K}(t, \mathbf{X})]\{\mathbf{X}\}=\{\mathbf{F}(t, \mathbf{X})\}+\left\{\mathbf{F}_{\mathbf{b}}(\mathbf{X}, \dot{\mathbf{X}})\right\}
$$


where $\mathbf{M}$ and $\mathbf{C}$ are the global constant mass and damping matrices, $\mathbf{X}, \dot{\mathbf{X}}, \ddot{\mathbf{X}}$ are the degree-of-freedom, velocity and acceleration vectors. The other terms are detailed hereafter:

- $\mathbf{K}(t, \mathbf{X})=\mathbf{K}_{\text {shaft }}+\mathbf{K}_{\text {gear }}(t, \mathbf{X})$ is the global stiffness matrix of the system with

- $\mathbf{K}_{\text {shaft }}$ : constant global stiffness matrix of the shafts

- $\mathbf{K}_{\text {gear }}(t, \mathbf{X})$ : global stiffness matrix of the gear which is time-dependant due to the evolution of the contact length on the base plane, and which is also potentially nonlinear due to the interaction between the degrees of freedom, tooth deviations and the extent of instantaneous contact [12]

- $\mathbf{F}(t, \mathbf{X})=\mathbf{F}_{\mathbf{0}}(t)+\mathbf{F}_{\text {gear }}(t, \mathbf{X})$ with

- $\mathbf{F}_{\mathbf{0}}(t)$ : external load vector (input and output torques, mass unbalance, etc)

- $\mathbf{F}_{\text {gear }}(t, \mathbf{X})$ : embodies the inertial effects caused by unsteady rotations (associated with no-load transmission error) and the contributions of geometrical errors and tooth shape deviations (pitch errors, tooth modifications, etc) [12]

- $\mathbf{F}_{\mathbf{b}}(\mathbf{X}, \dot{\mathbf{X}})$ are the hydrodynamic forces produced by the bearings and which oppose the motion of the shaft, as described in section 2 .

If the inertia center of the shaft is different from its geometrical center, then mass unbalance forces are embedded in the external load vector $\mathbf{F}_{\mathbf{0}}(t)$. In the frame $(\vec{s}, \vec{t}, \vec{z})$, these forces are written as

$$
\left\{\mathbf{F}_{\mathbf{m u}}\right\}_{(\vec{s}, \vec{z}, \vec{z})}=\left\{\begin{array}{c}
F_{m u S} \\
F_{m u T} \\
0
\end{array}\right\}=\left\{\begin{array}{c}
M e_{m u} \omega^{2} \cos (\omega t) \\
M e_{m u} \omega^{2} \sin (\omega t) \\
0
\end{array}\right\}
$$

for each shaft. In this expression, $M$ is the total mass of the shaft plus the pinion or gear and $e_{m u}$ represents the distance between the inertia and geometrical centers of the shaft.

In the proposed formulation (9), the contributions of bearings appear as forces external to the system. These hydrodynamic forces $\mathbf{F}_{\mathbf{b}}(\mathbf{X}, \dot{\mathbf{X}})$ and the contact conditions between the gear teeth make the system of equations Eq. (9) nonlinear. The nonlinear analysis requires a complex procedure combining iterative schemes for the treatment of the nonlinearities and a time-step integration process as described in section 4.2 , which will be referred to as nonlinear analysis. The solution technique can be significantly simplified by assuming small displacements in the vicinity of static position $\mathbf{X}_{\mathbf{0}}$ and linearizing Eq. (9), i.e., by using the linear analysis. Both kinds of analyses, nonlinear and linear, are detailed in the following section.

\subsection{Nonlinear dynamic analysis}

Because of the assumption of small perturbations, the linear theory cannot account for large dynamic loads. Solving the complete nonlinear problem Eq. (9) requires the simultaneous solution of the equations of motion, the Reynolds equation in the dynamic regime, and the contact conditions on the teeth. As a result, the solving procedure combines the Newmark time integration scheme with the Newton-Raphson incremental-iterative algorithm, and with an iterative normal contact algorithm that verifies that all the contact forces on the teeth are positive and no contact deflections occur outside the contact area [12]. The semidiscrete equation of motion Eq. (9) applied at time $t_{n+1}$ yields the following residual equation

$$
\mathbf{G}\left(\mathbf{X}_{n+1}\right)=\mathbf{M} \ddot{\mathbf{X}}_{n+1}+\mathbf{C} \dot{\mathbf{X}}_{n+1}+\mathbf{K} \mathbf{X}_{n+1}-\mathbf{F}_{n+1}-\mathbf{F}_{\mathbf{b}}\left(\mathbf{X}_{n+1}, \dot{\mathbf{X}}_{n+1}\right)=\mathbf{0}
$$

In order to reduce the set of variables in Eq. (11) to the displacements $\mathbf{X}_{n+1}$ only, the implicit Newmark algorithm is used. Choosing parameters $\gamma=1 / 2$ and $\beta=1 / 4$ to ensure unconditional stability and second-order accuracy, the velocities and accelerations at time $t_{n+1}$ are approximated with

$$
\begin{aligned}
& \dot{\mathbf{X}}_{n+1}=\frac{2}{\Delta t}\left(\mathbf{X}_{n+1}-\mathbf{X}_{n}\right)-\dot{\mathbf{X}}_{n} \\
& \ddot{\mathbf{X}}_{n+1}=\frac{4}{\Delta t^{2}}\left(\mathbf{X}_{n+1}-\mathbf{X}_{n}\right)-\frac{4}{\Delta t} \dot{\mathbf{X}}_{n}-\ddot{\mathbf{X}}_{n}
\end{aligned}
$$




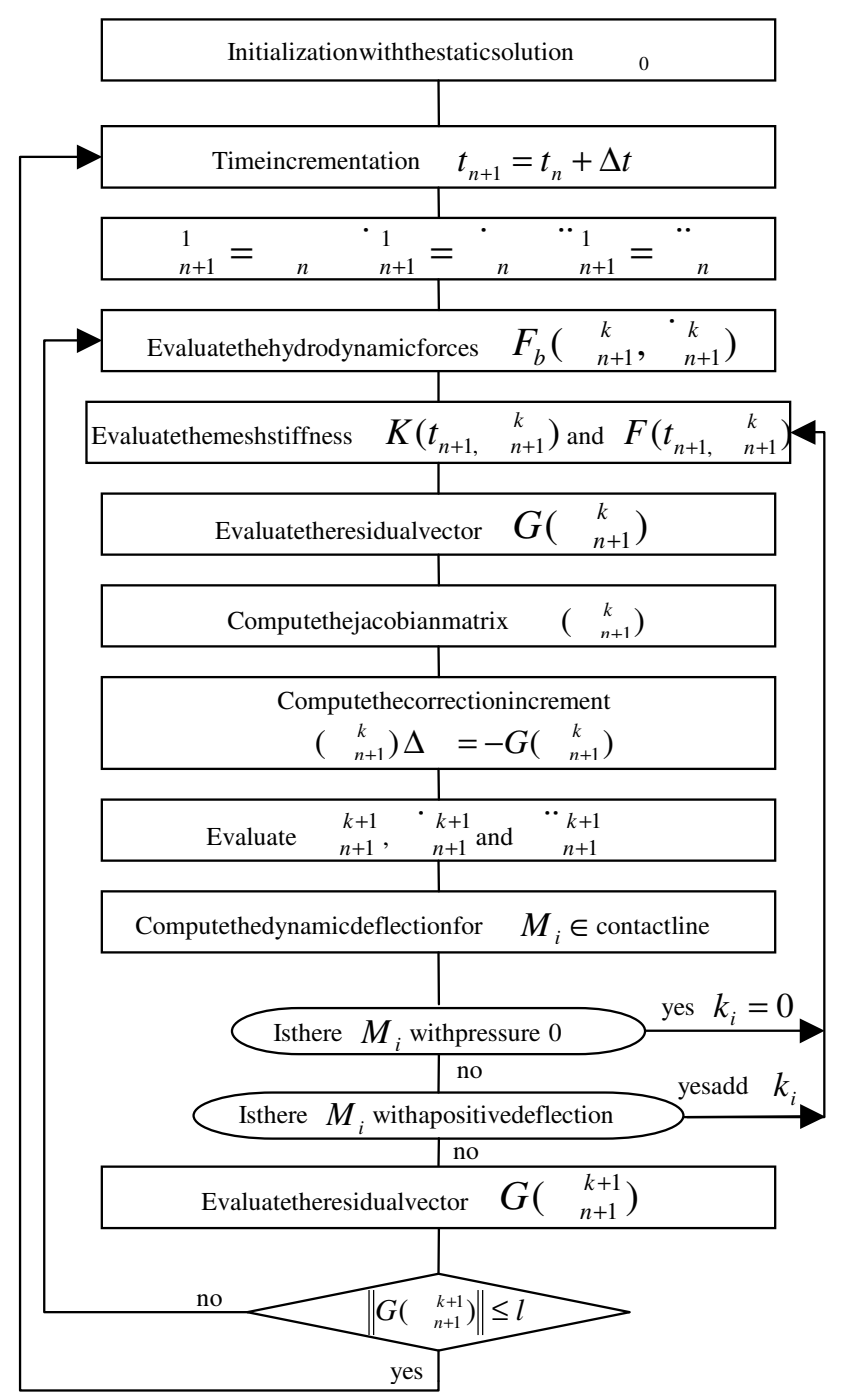

Figure 4: The algorithm with nested contact and dynamic iterative loops.

and replaced in Eq. (11). Since the resulting equation is nonlinear, it has to be solved by an iterative strategy. Therefore, the consistent linearization of Eq. (11) and the Newton-Raphson iteration technique are applied. The Taylor expansion of Eq. (11) at the first order results in the iterative equation

$$
\mathbf{J}_{n+1}^{k} \Delta \mathbf{X}=-\mathbf{G}\left(\mathbf{X}_{n+1}^{k}\right)
$$

in which $k$ represents the iteration index, $\mathbf{J}_{n+1}^{k}$ is the displacement-dependant Jacobian matrix at iteration $k$

$$
\mathbf{J}_{n+1}^{k}=\frac{\partial \mathbf{G}\left(\mathbf{X}_{n+1}^{k}\right)}{\partial \mathbf{X}_{n+1}}=\frac{4}{\Delta t^{2}} \mathbf{M}+\frac{2}{\Delta t} \mathbf{C}+\mathbf{K}-\frac{\partial \mathbf{F}_{\mathbf{b}}\left(\mathbf{X}_{n+1}^{k}, \dot{\mathbf{X}}_{n+1}^{k}\right)}{\partial \mathbf{X}_{n+1}}
$$

and $\Delta \mathbf{X}$ is the iterative change of the displacement vector

$$
\Delta \mathbf{X}=\mathbf{X}_{n+1}^{k+1}-\mathbf{X}_{n+1}^{k}
$$

The algorithmic set-up of this iterative procedure is presented in Fig. 4. The displacement is initialized with the 
static solution $\mathbf{X}_{\mathbf{0}}$, and initial velocity and acceleration vectors are set to zero. Once the residual vector has been computed with Eq. (11), a new displacement increment is obtained with Eq. (13), and the displacements, velocities and accelerations are updated with Eqs. (15) and Newmark approximations of Eq. (12). If these new conditions modify the gear contact conditions, the mesh stiffness $\mathbf{K}\left(t_{n+1}, \mathbf{X}_{n+1}^{k}\right)$ and the load vector $\mathbf{F}\left(t_{n+1}, \mathbf{X}_{n+1}^{k}\right)$ are updated, otherwise the residual vector $\mathbf{G}$ is re-evaluated. If the norm of the residual $\mathbf{G}$ is below a user-defined convergence limit $l$, then a converged solution is obtained and the algorithm moves to the next time step, else the hydrodynamic forces are re-evaluated and a new Newton-Raphson iteration is started.

The derivative of the fluid forces in the Jacobian Eq. (14) depends on both $\mathbf{X}_{n+1}^{k}$ and $\dot{\mathbf{X}}_{n+1}^{k}$ and therefore needs to be updated for each Newton-Raphson iteration. It is given by

$$
\frac{\partial \mathbf{F}_{\mathbf{b}}\left(\mathbf{X}_{n+1}^{k}, \dot{\mathbf{X}}_{n+1}^{k}\right)}{\partial \mathbf{X}_{n+1}}=\frac{\partial \mathbf{F}_{\mathbf{b}}}{\partial \mathbf{X}_{n+1}}+\frac{2}{\Delta t} \frac{\partial \mathbf{F}_{\mathbf{b}}}{\partial \dot{\mathbf{X}}_{n+1}}
$$

Using the hybrid method presented in section 2.2.2, the two derivatives of $\mathbf{F}_{\mathbf{b}}$ with respect to $\mathbf{X}_{n+1}$ and $\dot{\mathbf{X}}_{n+1}$ are obtained at almost no extra cost, in contrast to classical numerical differentiation which requires at least four fluid force computations per bearing.

\subsection{Linear dynamic analysis}

\subsubsection{Linearized 8-coefficient model}

Assuming that displacements and velocities remain small in the vicinity of the static position $\mathbf{X}_{\mathbf{0}}$, a first order expansion of the dynamic bearing force yields

$$
\mathbf{F}_{\mathbf{b}}(\mathbf{X}, \dot{\mathbf{X}})=\left\{\mathbf{F}_{\mathbf{b} \mathbf{0}}\right\}-\left[\mathbf{K}_{\mathbf{b}}\right]\{\Delta \mathbf{X}\}-\left[\mathbf{C}_{\mathbf{b}}\right]\{\Delta \dot{\mathbf{X}}\}
$$

where $\Delta \mathbf{X}=\mathbf{X}-\mathbf{X}_{\mathbf{0}}, \Delta \dot{\mathbf{X}}=\dot{\mathbf{X}}$, and $\mathbf{F}_{\mathbf{b 0}}=\mathbf{F}_{\mathbf{b}}\left(\mathbf{X}_{\mathbf{0}}\right)$ is obtained by Eq. (2). The stiffness and damping matrices [ $\left.\mathbf{K}_{\mathbf{b}}\right]_{s t}$ and $\left[\mathbf{C}_{\mathbf{b}}\right]_{s t}$ are obtained by differentiation of the dynamic bearing force $\mathbf{F}_{\mathbf{b}}$ in frame $(\vec{s}, \vec{t}, \vec{z})$

$$
\left[\mathbf{K}_{\mathbf{b}}\left(\mathbf{X}_{\mathbf{0}}\right)\right]=-\frac{\partial \mathbf{F}_{\mathbf{b}}\left(\mathbf{X}_{\mathbf{0}}\right)}{\partial \mathbf{X}} \quad\left[\mathbf{C}_{\mathbf{b}}\left(\mathbf{X}_{\mathbf{0}}\right)\right]=-\frac{\partial \mathbf{F}_{\mathbf{b}}\left(\mathbf{X}_{\mathbf{0}}\right)}{\partial \dot{\mathbf{X}}}
$$

Each journal bearing is therefore replaced with four stiffness and four damping coefficients. These coefficients are computed by the hybrid method and then kept constant all along the dynamic simulation. Eqs. (17) and (9) result in the linear system

$$
[\mathbf{M}]\{\Delta \ddot{\mathbf{X}}\}+\left[\mathbf{C}_{0}\right]\{\Delta \dot{\mathbf{X}}\}+\left[\mathbf{K}_{0}\right]\{\Delta \mathbf{X}\}=\{\mathbf{F}(t, \mathbf{X})\}+\left\{\mathbf{F}_{\mathbf{b} \mathbf{0}}\right\}
$$

where

$$
\begin{aligned}
{\left[\mathbf{C}_{0}\right] } & =[\mathbf{C}]+\left[\mathbf{C}_{\mathbf{b}}\left(\mathbf{X}_{\mathbf{0}}\right)\right] \\
{\left[\mathbf{K}_{0}\right] } & =\left[\mathbf{K}_{\text {shaft }}\right]+\left[\mathbf{K}_{\text {gear }}\right]+\left[\mathbf{K}_{\mathbf{b}}\left(\mathbf{X}_{\mathbf{0}}\right)\right]
\end{aligned}
$$

The linear differential system Eq. (19) is solved by the implicit Newmark time-step integration scheme combined with a normal contact algorithm aimed at updating the dynamic characteristics of the meshing process.

\section{Numerical results and discussion}

The gear, shaft and bearing data used in the numerical simulations are given in Tables 1, 2 and 3. The gear has no profile and lead corrections. A unique modal damping factor of 0.03 was used for all the numerical simulations and the time increment $\Delta t$ was set to $1 / 32^{\text {th }}$ of the mesh period in order to capture mesh stiffness variations. All the simulations were performed over 2048 mesh periods, i.e. 65536 time increments, which correspond approximately to 10 gear revolutions and 60 pinion revolutions, thereby causing the transient effects to disappear and the motion to become periodic. 
Table 1: Main parameters for the gear and pinion.

\begin{tabular}{lccc}
\hline Data & Pinion & Gear \\
\hline Number of teeth $Z$ & 26 & & 157 \\
Face width $b(\mathrm{~mm})$ & 50 & & 40 \\
Helix angle $\beta\left(^{\circ}\right)$ & & 0 & \\
Module $m(\mathrm{~mm})$ & & 4 & \\
Pressure angle $\alpha\left(^{\circ}\right)$ & & 20 & \\
Dedendum coefficient & 1. & & 1. \\
Addendum coefficient & 1.4 & & 1.4 \\
Profile shift coefficient & 0.16 & & -0.16 \\
Center distance $d(\mathrm{~mm})$ & & 366 & \\
Mass $M_{i}(\mathrm{~kg})$ & 2 & & 74 \\
\hline
\end{tabular}

Table 2: Shaft data.

\begin{tabular}{|c|c|c|c|}
\hline Data & Pinion shaft & & Gear shaft \\
\hline Outer diameter $2 R_{o}(\mathrm{~mm})$ & 70 & & 90 \\
\hline Inner diameter $2 R_{i}(\mathrm{~mm})$ & 30 & & 30 \\
\hline Shaft length $L(\mathrm{~mm})$ & & 160 & \\
\hline Young's modulus $E(\mathrm{MPa})$ & & 210000 & \\
\hline Poisson's ratio $v$ & & 0.3 & \\
\hline Density $\rho\left(\mathrm{kg} \mathrm{m}^{-3}\right)$ & & 7800 & \\
\hline
\end{tabular}

Table 3: Bearing data.

\begin{tabular}{lcc}
\hline Data & Bearings 1 and 2 (Pinion shaft) & Bearings 3 and 4 (Gear shaft) \\
\hline Diameter $2 R(\mathrm{~mm})$ & 70 & 90 \\
Length $L(\mathrm{~mm})$ & 50 & 65 \\
Radial clearance $C(\mu \mathrm{m})$ & 150 & 110 \\
Dynamic viscosity $\mu($ Pa.s $)$ & & 0.0288 \\
\hline
\end{tabular}

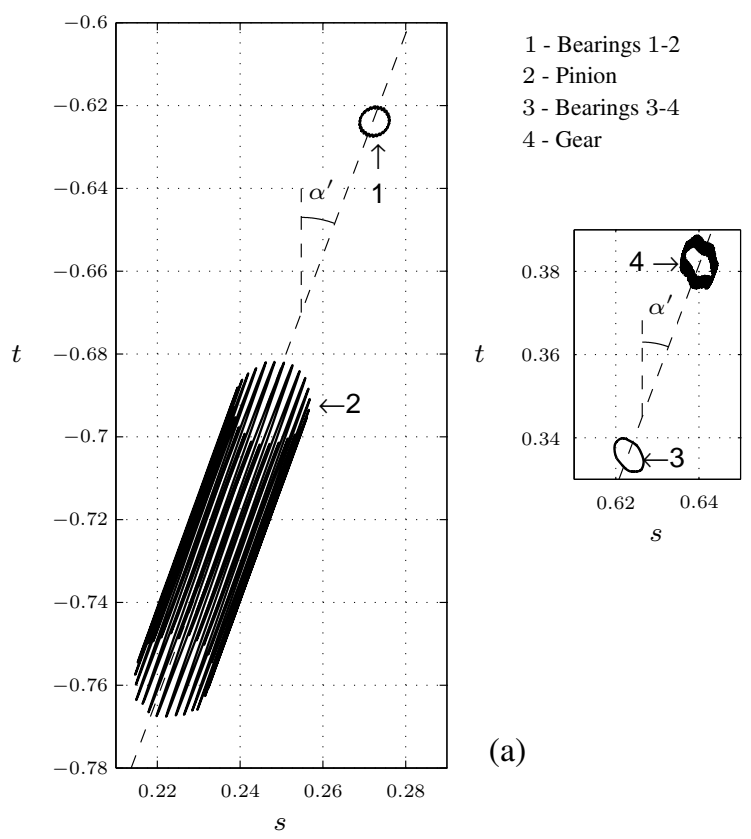

(b)

Figure 5: Periodic orbits of pinion and gear, and shaft orbits in bearings 1 and 3 for a spur gear. 

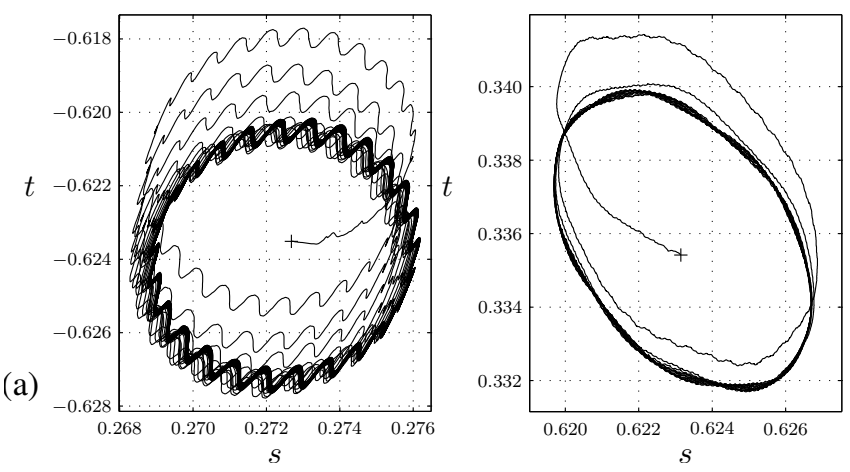

(b)

Figure 6: Zoom of Fig. 5 on the orbit of shaft 1 in bearing 1 (a) and shaft 2 in bearing 3 (b).

\subsection{Gear-bearing interaction}

The first simulation was performed with a spur gear at input speed $\omega=325 \mathrm{rad} / \mathrm{s}$, input torque $T=220$ N.m and with the mass unbalance forces in Eq. (10) computed with $e_{m u}=0.6 \mathrm{~mm}$. Periodic orbits of shaft nodes corresponding to bearings and gears are presented in Fig. 5a and Fig. 5b for the input and output shafts respectively. All the orbits are dimensionless with respect to bearing clearance $C$, so that all the shaft orbits in the bearings are included in a unitary circle. Since the gear assembly is perfectly symmetrical (see Fig. 1), the orbits in bearings 1 and 2 are identical. For the same reason, the orbits in bearings 3 and 4 are also identical. Fig. 5 shows that shaft bending occurs as expected in the base plane, and that bending is maximum at the pinion and gear centers. All the orbits oscillate in the direction of the line of action. These oscillations are superimposed on the elliptical motion related to the mass unbalance and are prevalent for the pinion (orbit 2 on Fig. 5a).

The corresponding transient motion of the shaft center in bearing 1 (input/pinion shaft) is plotted in Fig. 6a. The complete motion is composed of 60 loops. The stabilized orbits exhibit 26 oscillations associated with the pinion mesh period and demonstrate the interaction between the gears and the bearings. The influence of gear excitations and their direction along the base plane can be clearly identified on the pinion orbits. The norm of the hydrodynamic forces over the last orbit, i.e. the last 26 mesh periods of the pinion, is plotted in Fig. 7a for the same bearing. This force diagram allows identifying a constant fundamental component that corresponds to the transmitted load, one superimposed low-frequency oscillation with a one-per-revolution period related to mass unbalance, and 26 higherfrequency oscillations standing for the mesh excitations of the pinion. These contributions of unbalance excitation and mesh excitations (multiple of the number of teeth of the pinion and the gear) can be also identified in Fig. 7a which shows the Fourier transform of the signal. The same conclusions stand for bearing 3 (output shaft), where orbits exhibit 157 high-frequency oscillations associated with the gear meshing period, as shown in Figs. 6b and 7c. The FFT-plots are made dimensionless with respect to the highest component amplitude of the nonlinear model spectrum. Moreover, on these plots, the normalized frequency $\bar{f}$ unit is equal either to the pinion rotation frequency for bearing 1 or to the gear rotation frequency for bearing 3. The consequence of this normalization, for bearing 1 (Fig. 7a) is that excitation due to unbalance on the pinion shaft appears for $\bar{f}_{p}=1$, while the meshing excitation has frequency $\bar{f}_{m}=26$, corresponding to the 26 mesh periods during one pinion rotation. Similarly, for bearing 3 (Fig. 7c), the excitation due to the unbalance on the gear shaft appears for $\bar{f}_{g}=1$, the excitation due to unbalance on the pinion shaft appears for $\bar{f}_{p}=157 / 26=6.03$, and the meshing excitation has frequency $\bar{f}_{m}=157$. The presence of these three frequencies in the response confirms not only the interaction between the gear and the bearings but also the coupling between the two shafts through the gear.

\subsection{Comparison of the models}

This section presents some comparisons between the different bearing models. The first paragraph introduces comparisons between the available numerical methods for the computation of fluid forces in the bearings. A second paragraph illustrates the differences between the linear and nonlinear models. The same set of parameters as before is used for the computations: $\omega=325 \mathrm{rad} / \mathrm{s}, T=220 \mathrm{~N} . \mathrm{m}, e_{m u}=0.6 \mathrm{~mm}$. 



Figure 7: Norm and FFT of the hydrodynamic forces in bearings 1 and 3 for a spur gear.

\begin{tabular}{cccccr}
\multicolumn{5}{c}{ Table 4: Computational times for the different models. } \\
\hline Case & Method & Mesh & Reynolds equations & Time & Error \\
\hline 0 & L. - H.M. & 192 & 32 & 0.60 & $0.02 \%$ \\
1 & N.L. - S.B.T. & $\times$ & $290 \times 10^{3}$ & 0.69 & $12.40 \%$ \\
2 & N.L. - H.M. & 192 & $264 \times 10^{3}$ & 1 & $0.02 \%$ \\
3 & N.L. - H.M. & 384 & $264 \times 10^{3}$ & 1.36 & $0.005 \%$ \\
4 & N.L. - M.M. & $192 \times 32$ & $1012 \times 10^{3}$ & 130 & Ref. \\
\hline
\end{tabular}

The following abbreviations used: $L .=$ Linear model, $N . L .=$ Nonlinear model, H.M.=Hybrid Method, S.B.T.=Short Bearing Theory, M.M.=Multigrid Method. 


\subsubsection{Comparison of the different computational methods for fluid forces}

Table 4 provides two results: the first concerns the accuracy of the different methods in the evaluation of the fluid forces in the bearings, followed by their influence on the overall computational cost of the dynamic algorithm proposed in this paper. To do this, the eccentricity of the initial static position in bearing 1 is compared to that obtained by the multigrid method serving as reference. Then, the nonlinear transient dynamic simulation is performed, 10 gear revolutions are computed, i.e. 2048 mesh periods or 65536 time increments with the convergence limit set to $l=10^{-5}$. The corresponding total CPU-time is reported in Table 4 along with the number of Reynolds equations solved during the dynamic simulation.

Five different methods are considered. Case 0 corresponds to a linear dynamic analysis (see section 3.3) and cases 1 to 4 correspond to a nonlinear analysis (see section 3.2). For a linear analysis the Jacobian matrices are computed only once and kept constant throughout the simulation, whereas for a nonlinear simulation they must be computed at every time step. Other differences are listed hereafter. For case 0 , the linearized 8-coefficient model is used to evaluate the bearing forces during the dynamic simulation. The initial static solution $\mathbf{X}_{\mathbf{0}}$ and the corresponding fluid forces and Jacobian matrices are determined numerically with the hybrid method. For case 1, the fluid forces and Jacobian matrices are computed analytically using the short bearing theory [5]. For case 2, the hybrid method is used to compute fluid forces and Jacobian matrices. Case 3 is similar to case 2, with a denser bearing mesh. Finally, the multigrid method is used to compute bearing forces for case 4, and Jacobian matrices are computed with a first order numerical differentiation.

For the same level of mesh refinement (cases 0, 2 and 4), the relative error on $\mathbf{X}_{\mathbf{0}}$ between the hybrid method and the reference multigrid method is only $0.02 \%$. The minor improvement of the accuracy of the hybrid method with a denser mesh (case 3 ) is not worth the extra computational cost. The short bearing theory (case 1) does not provide an accurate initial static solution $\mathbf{X}_{\mathbf{0}}$ because the ratio $L / D=0.72$ of Table 3 does not fit in the validity range of the short bearing theory $(L / D<1 / 8)$.

Case 2 is used as the reference for the computational cost. Eight minutes are needed to perform this simulation. As expected, the linear simulation (case 0 ) requires less CPU-time because only the initial static solution requires several resolutions of the Reynolds equation. For all the nonlinear simulations, each of the 65536 time steps requires approximately 3 Newton-Raphson iterations, and each iteration requires several resolutions of the Reynolds equation, therefore CPU-time is longer. The hybrid method (case 2) makes the overall dynamic algorithm 130 times faster than the multigrid method. This is not only explained by the fact that fewer Reynolds equations are solved since the Jacobian matrices are not computed by numerical differentiation, but also by the efficient separation of variables used by the method. The hybrid method is also reported to be 100 times faster than a finite element method in Zheng et al. [30].

All the following calculations use the hybrid method with the mesh corresponding to case 2 as it turns out to be a good compromise between accuracy and computational cost.

\subsubsection{Comparison of linear and nonlinear algorithms}

Figure 7 presents results from the linearized 8-coefficient and the nonlinear models of section 3. For each model the norm of the hydrodynamic forces $\left\|\mathbf{F}_{\mathbf{b}}\right\|$ in bearings 1 and 3 and the spectrum of these forces are presented. The plots correspond to the steady-state orbits of Fig. 6, i.e. to the last 26 mesh periods for bearing 1 on the pinion shaft, and to the last 157 mesh periods for bearing 3 on the gear shaft. The hydrodynamic forces computed with the linearized 8-coefficient model and the nonlinear model are identical in bearing 1 (Figs. 7(a)-(b)) as well as in bearing 3 (Figs. 7(c)-(d)). The fundamental frequencies $\bar{f}_{g}, \bar{f}_{p}$ and $\bar{f}_{m}$ are clearly identified on these charts, as are the harmonics of order 2, 3, 5 and 6 of $\bar{f}_{m}$. The linearized 8 -coefficient model performs very well because the dynamic solution (Fig. 6) remains close to the static solution, so that the assumption of small displacements and velocities in the vicinity of the static position $\mathbf{X}_{\mathbf{0}}$ is valid. Fig. 8 compares the evolution of the dynamic tooth load factor $\mathscr{R}$ in the gear with the peak-to-peak value of the norm of the hydrodynamic forces $\left\|\mathbf{F}_{\mathbf{b}}\right\|$ in bearings 1 and 3 . The dynamic tooth load factor is defined as the maximum dynamic-to-maximum static mesh load ratio. The comparison is performed with the same set of parameters as before and with an input rotation speed ranging from $100 \mathrm{rad} / \mathrm{s}$ to $1200 \mathrm{rad} / \mathrm{s}$. As shown in Fig. 8, the bearing forces and the dynamic tooth load factor $\mathscr{R}$ obtained at different speeds exhibit a nonlinear behavior. Considering bearing forces, the two models give similar results due to the small displacements in the vicinity of the static position. The dynamic tooth load factor $\mathscr{R}$ seems to be insensitive to the model used to evaluate bearing forces, as shown in Fig. 8a. The dynamic tooth load factors obtained by the two models are very close and are dominated by 

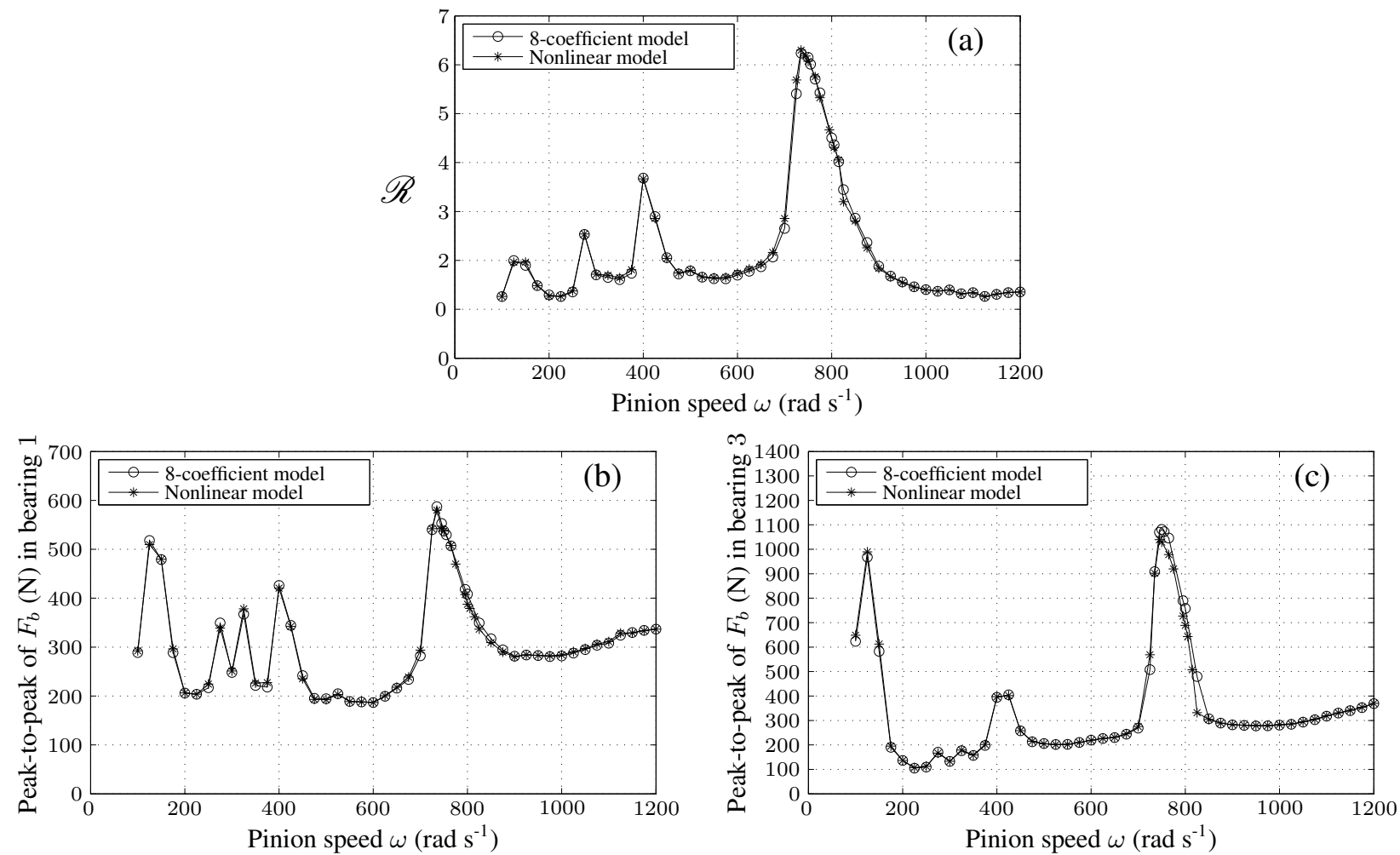

Figure 8: Comparison of the different bearing models: (a) Dynamic tooth loading $\mathscr{R}$, (b) Peak-to-peak value of hydrodynamic load $F_{b}$ in bearing 1 and (c) Peak-to-peak value of hydrodynamic load $F_{b}$ in bearing 3 . 


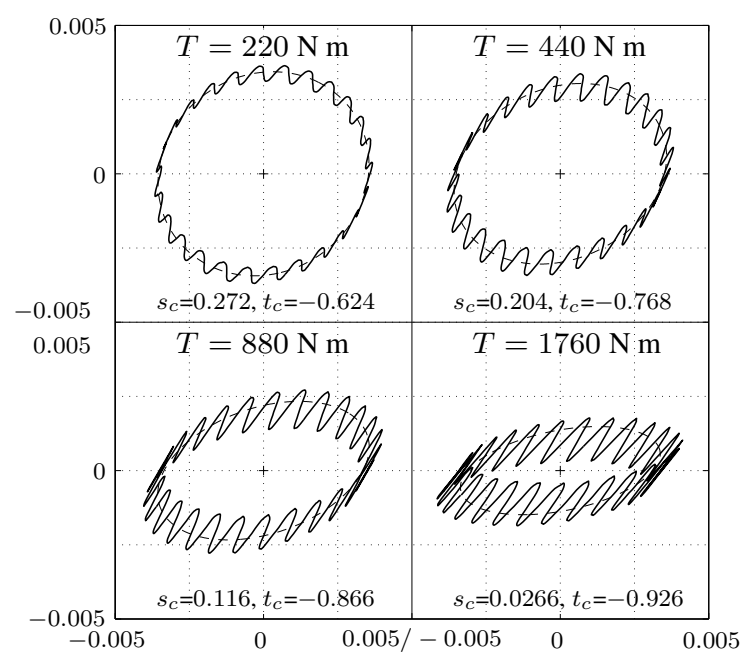

Figure 9: Influence of the input torque: Orbits of shaft 1 in bearing 1 for a spur gear $(\omega=325 \mathrm{rad} / \mathrm{s})$.

amplitude jumps and shocks at the critical frequencies.

It can also be observed that Fig. 8a and Figs. 8b-c are correlated. The dynamic tooth load factor $\mathscr{R}$ and the hydrodynamic forces obtained with the linearized 8-coefficient and nonlinear bearing models exhibit very similar evolutions. This confirms the previous conclusion about the interaction between the gear and the bearings.

\subsection{Influence of parameters}

\subsubsection{Influence of input speed}

The input speed of rotation $\omega$ has a major influence. As already stated in the previous section, it has a nonlinear influence on the peak-to-peak value of $\left\|\mathbf{F}_{\mathbf{b}}\right\|$ and on the dynamic tooth loading factor $\mathscr{R}$ (see Fig. 8). The input rotation speed also governs the static positioning of the shafts in the bearings. The shaft eccentricities are all the smaller as the speed is high. Moreover the size of the steady-state orbits of the shafts in the bearings depends on the mass unbalance, on the hydrodynamic forces and on the dynamic tooth loading which in turn depend in a nonlinear way on the rotation speed.

\subsubsection{Influence of input torque}

Increasing the transmitted load leads to higher strains in the structure, to higher mesh excitations in the gear and to higher hydrodynamic loads in the journal bearings. As a result, the eccentricity of the shafts in the bearings is increased. This is illustrated in Fig. 9 which shows the steady-state orbit of the input shaft in bearing 1 for a constant rotation speed $\omega=325 \mathrm{rad} / \mathrm{s}$ and increasing input torque values. Each orbit is approximated with an ellipse using a least-square method and the coordinates $\left(s_{c}, t_{c}\right)$ of the center of the ellipse give the mean eccentricity of the bearing. As the input torque increases the shaft eccentricity also increases, as do the oscillations on the orbits due to higher meshing forces. The shape of the orbit changes due to increasing hydrodynamic and mesh forces while its diameter remains the same due to a fixed mass unbalance at the given rotation speed. The motion is therefore dominated by mesh excitations for high values of the torque whereas it is dominated by mass unbalance for smaller values.

\subsubsection{Influence of mass unbalance}

The diameter of the shaft orbits is set by the amplitude of mass unbalance. When mass unbalance increases, the displacements become larger and the dynamic motion no longer remains in the vicinity of the static position. As a consequence, the 8-coefficient linear bearing model is no longer valid and gives inaccurate results. To illustrate this, the peak-to-peak value of the hydrodynamic forces $\mathbf{F}_{\mathbf{b}}$ in bearing 1 is plotted in Fig. 10a for different values of unbalance amplitude $e_{m u}$ and an input speed varying from 100 to $1200 \mathrm{rad} / \mathrm{s}$. Differences between the linear and the nonlinear models are clearly visible at high speeds. They are all the greater as the mass unbalance amplitude $e_{m u}$ increases. On the other hand, mass unbalance forces barely affect the dynamic factor $\mathscr{R}$, as shown in Fig. $10 \mathrm{~b}$. 

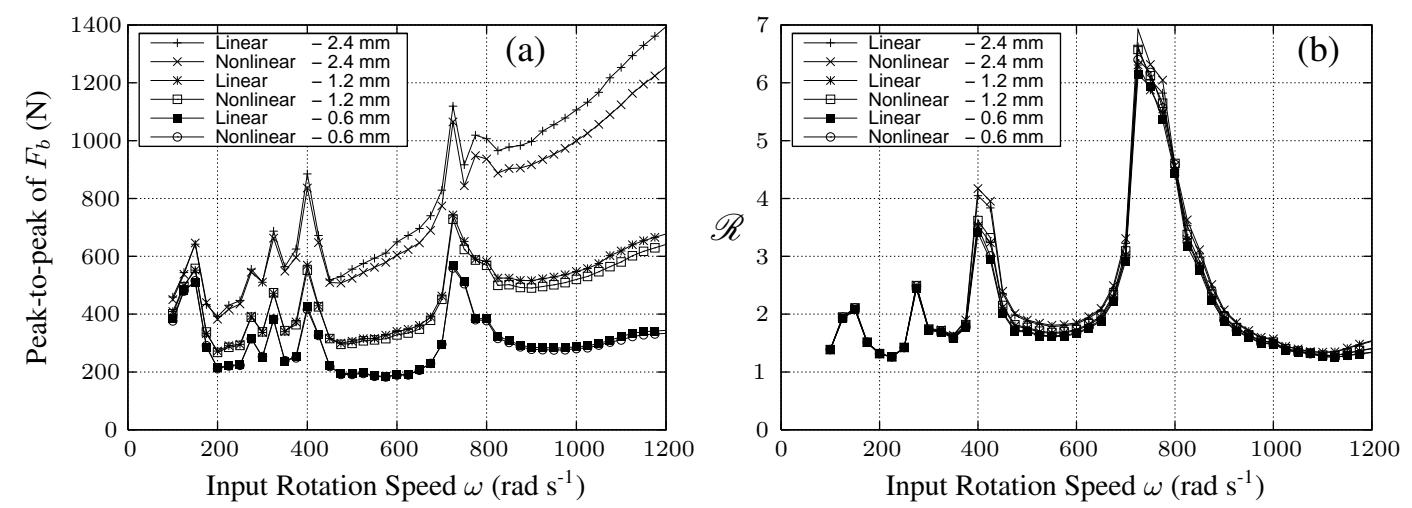

Figure 10: Influence of mass unbalance: (a) Peak-to-peak value of the hydrodynamic load $F_{b}$ in bearing 1 , (b) Dynamic tooth loading $\mathscr{R}$ for a spur gear. ( $T=220$ N.m, $\omega=325 \mathrm{rad} / \mathrm{s}$ )

\subsubsection{Influence of gear helix angle}

Figure 11(a) shows the evolution of $\mathscr{R}$ for increasing values of helix angle $\beta$. The peaks correspond to high dynamic loading or shocks between gear teeth while in operation and can be used to identify critical rotation speeds. These peaks exist whatever the value of $\beta$ and their amplitude decreases when $\beta$ is increased. This is a well known smoothing property of helical gears, due to the increase of the contact ratio when helix angle $\beta$ increases. The peakto-peak value of hydrodynamic forces $\left\|\mathbf{F}_{\mathbf{b}}\right\|$ in bearings 1 and 2 is plotted in Figs. 11(b) and 11(c). As expected, these plots exhibit the same behavior as the dynamic coefficient $\mathscr{R}$ and the same dependence on helix angle $\beta$. This confirms once again the coupling and the proper transfer between the gear and the bearings. A comparison between the transient motion of shaft 1 in bearings 1 and 2, and shaft 2 in bearings 3 and 4 respectively, for spur and helical gears is proposed in Fig. 12. The figure shows the transient motion from the static solution $\mathbf{X}_{\mathbf{0}}$ to the steady-state solution for an input rotation speed $\omega=325 \mathrm{rad} / \mathrm{s}$, an input torque $T=220 \mathrm{~N} . \mathrm{m}$ and an unbalance amplitude on each shaft $e_{m u}=0.6 \mathrm{~mm}$. For spur gears, the steady-state orbits in bearings 1 and 2, bearings 3 and 4 respectively, are both centered on the static solution $\mathbf{X}_{\mathbf{0}}$ due to the symmetry of the system. For helical gears, this is no longer the case. The steady-state orbits shift to each side of the static solution, resulting in shaft misalignment. This shift depends on several parameters among which the helix angle $\beta$ and profile and lead correction parameters. This deviation can be explained by different load distributions on gear teeth for spur and helical gears as plotted in Fig. 13. The load distribution is uniform along the gear width for the spur gear, whereas it is not for the helical gear. This non-uniform load leads to a loss of balance that changes the position of the shafts in the bearings. The influence of helix angle $\beta$ is analyzed in Fig. 14, where the steady-state periodic orbit of shaft 1 in bearing 1 is plotted for increasing values of $\beta$ at input speed $\omega=325 \mathrm{rad} / \mathrm{s}$. The first $\left(\beta=0^{\circ}\right)$ and last $\left(\beta=12.5^{\circ}\right)$ orbits correspond to the orbits in bearing 1 in Fig. 12(a). All these orbits differ in two ways. First, considering the coordinates of the center written below each orbit, it can be seen that these orbits are not centered on the same point. Moreover, the distance from the static position increases with $\beta$. Second, the meshing oscillations superimposed on the basic mass unbalance orbits become smaller with the increase of the helix angle, in good agreement with the decrease of the dynamic coefficient $\mathscr{R}$ observed in Fig. 11(a). All the orbits have the same size, which indicates that the unbalance excitation is not affected by the variation of the helix angle.

Since the meshing excitations are transmitted to the bearings through the shafts, hydrodynamic forces $\mathbf{F}_{\mathbf{b}}$ in the bearings are also affected by the variation of the helix angle. Hydrodynamic forces in bearings 1 and 3 for a helical gear $\left(\beta=12.5^{\circ}\right)$ are plotted in Figs. 15(a) and 15(c) respectively. Compared to Figs. 7(a) and 7(c) related to a spur gear, these figures confirm that helical gears soften mesh excitations. High frequency oscillations are remarkably reduced when helix angle $\beta$ is increased. FFT analyses, which are made dimensionless with respect to the higher amplitude of the spur gear spectrum, illustrate this filtering action. All the peaks corresponding to multiples of the mesh excitations have disappeared with the helical gear which acts as a low-pass filter.

A comparison between the linear and nonlinear models was also performed for $\beta=12.5^{\circ}$. The resulting loads and corresponding FFT are plotted in Figs. 15(a)-(d). The evolution of dynamic factor $\mathscr{R}$ and the peak-to-peak value of 

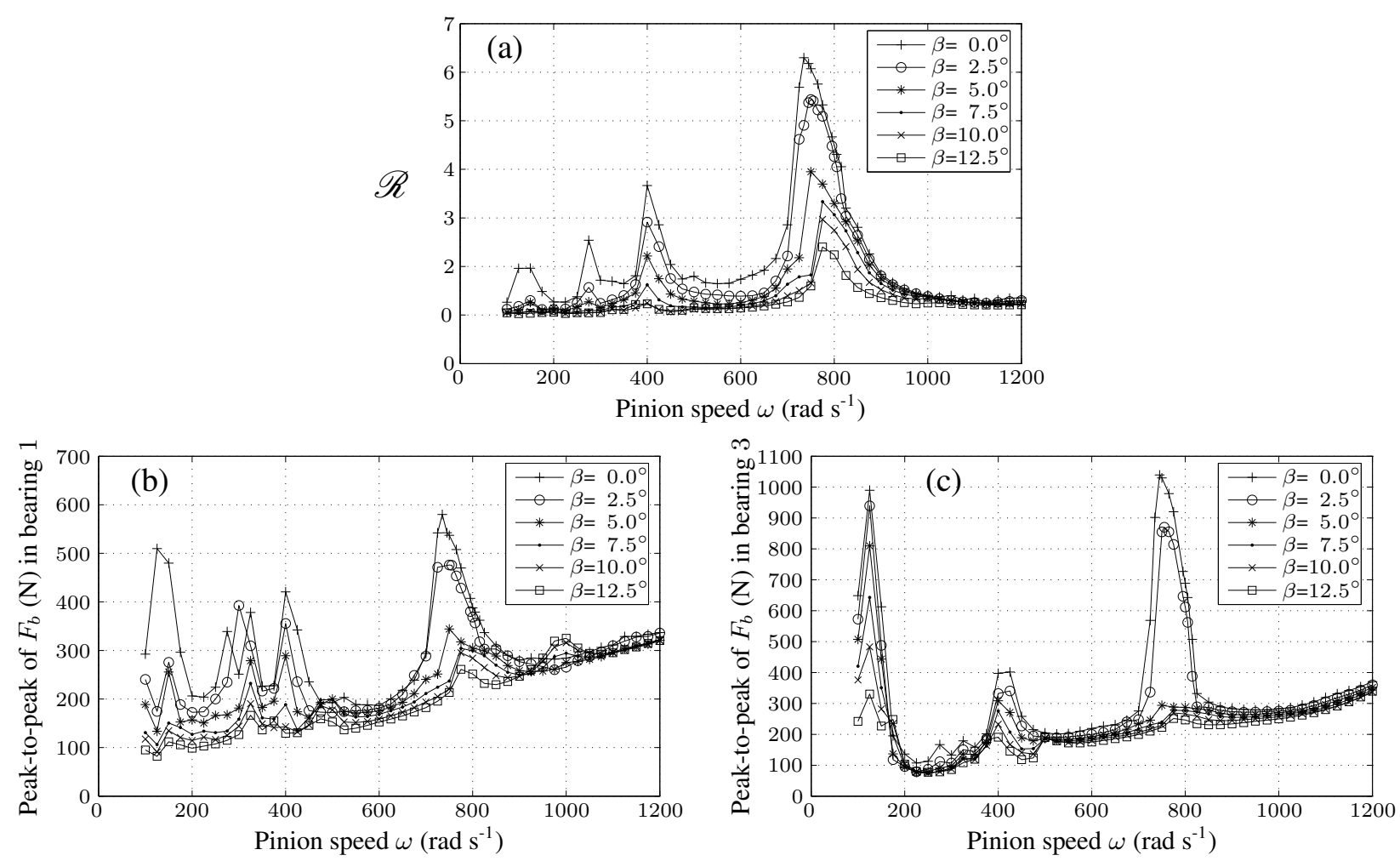

Figure 11: Influence of helix angle $\beta$ on the dynamic load: (a) Dynamic tooth loading $\mathscr{R}$, (b) Peak-to-peak value of the hydrodynamic load $F_{b}$ in bearing 1, (c) Peak-to-peak value of $F_{b}$ in bearing 3 .
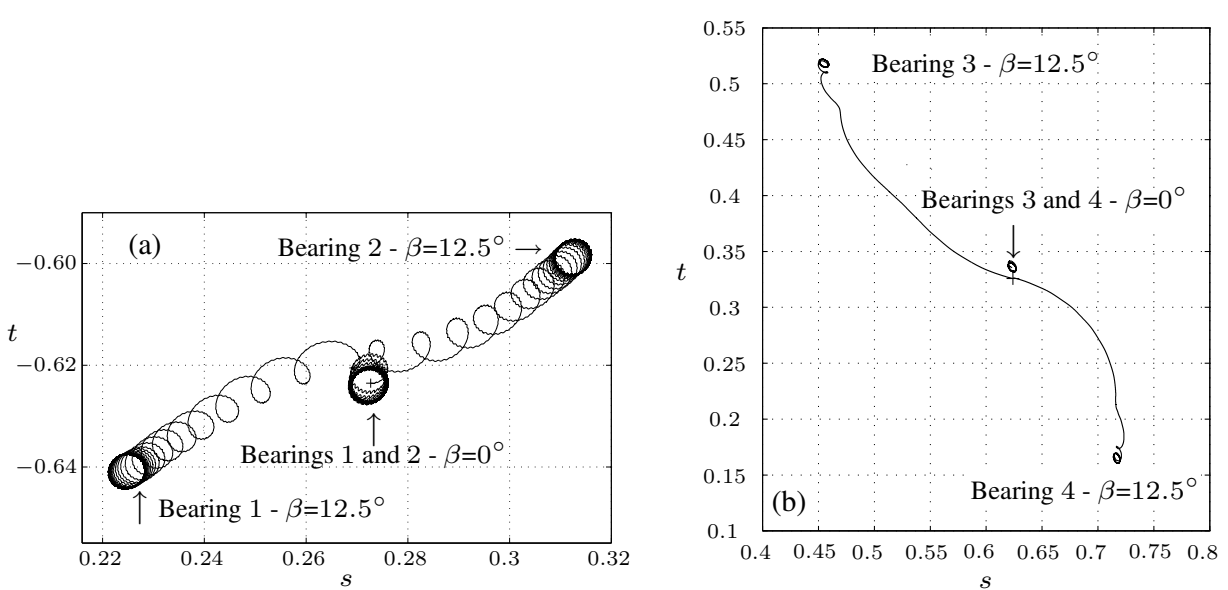

Figure 12: Influence of the helix angle $\beta$ on the transient motion for a spur gear $\beta=0^{\circ}$ and a helical gear $\beta=12.5^{\circ}$ at $\omega=325 \mathrm{rad} / \mathrm{s}$. (a) shaft $1 \mathrm{in}$ bearings 1 and 2, (b) shaft 2 in bearings 3 and 4 . 

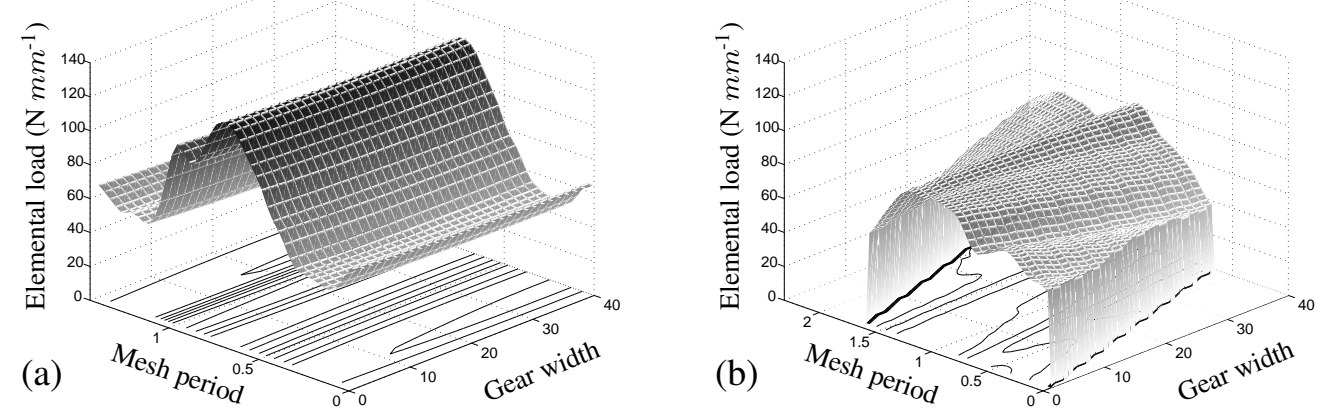

Figure 13: Load distribution along the gear width obtained with the present distributed meshing formulation: (a) spur gear and (b) helical gear $\beta=12.5^{\circ}$.

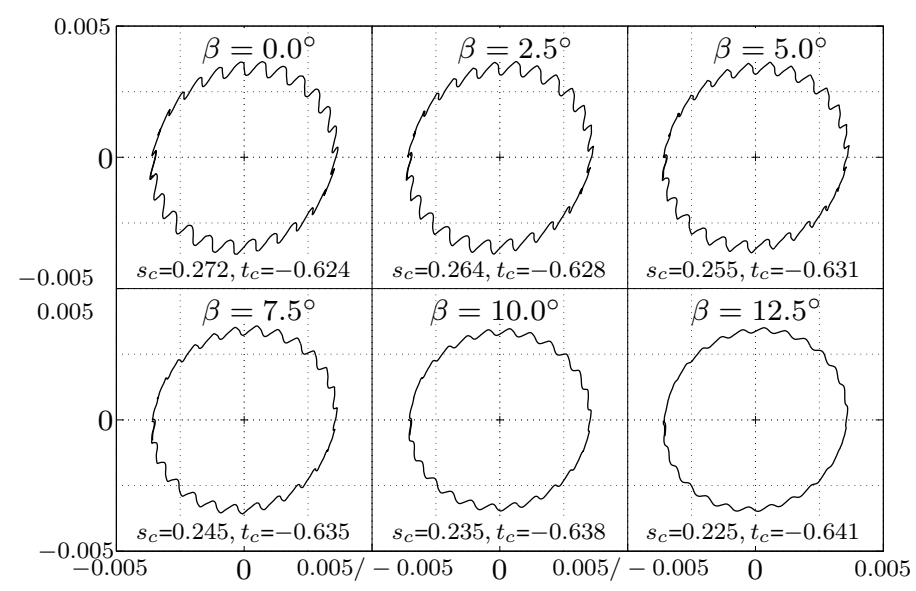

Figure 14: Influence of the helix angle $\beta$ on the orbits of shaft 1 in bearing 1 at $\omega=325 \mathrm{rad} / \mathrm{s}$ for $\beta$ ranging from 0 to $12.5^{\circ}$. 

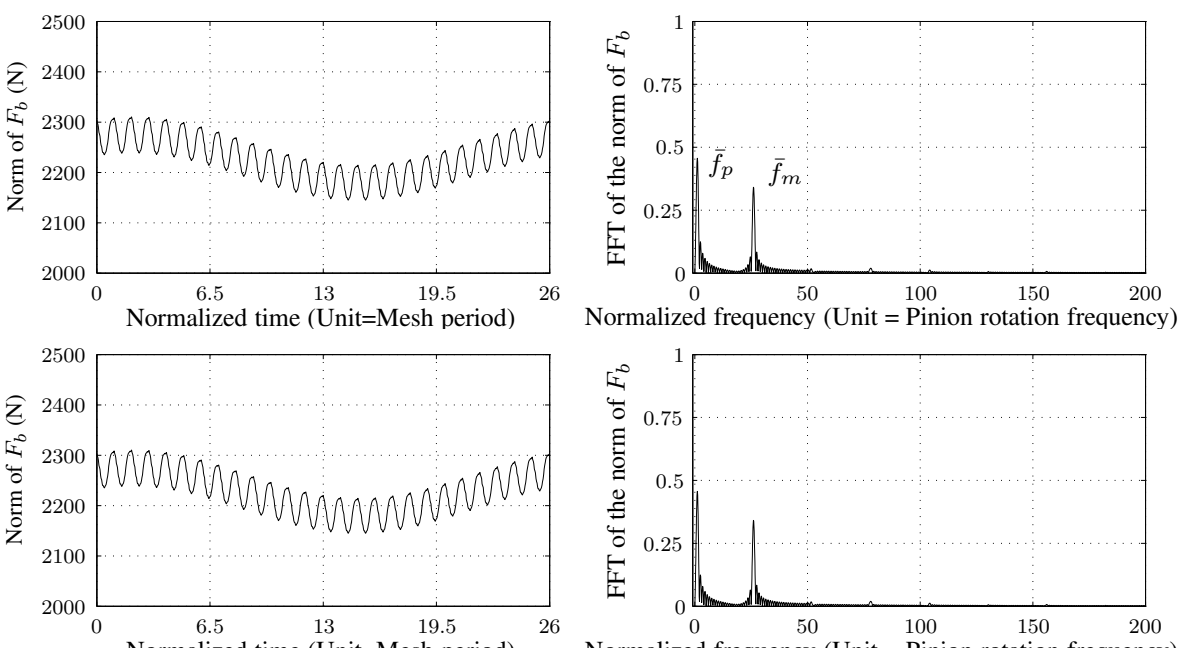

Normalized frequency $($ Unit $=$ Pinion rotation frequency)
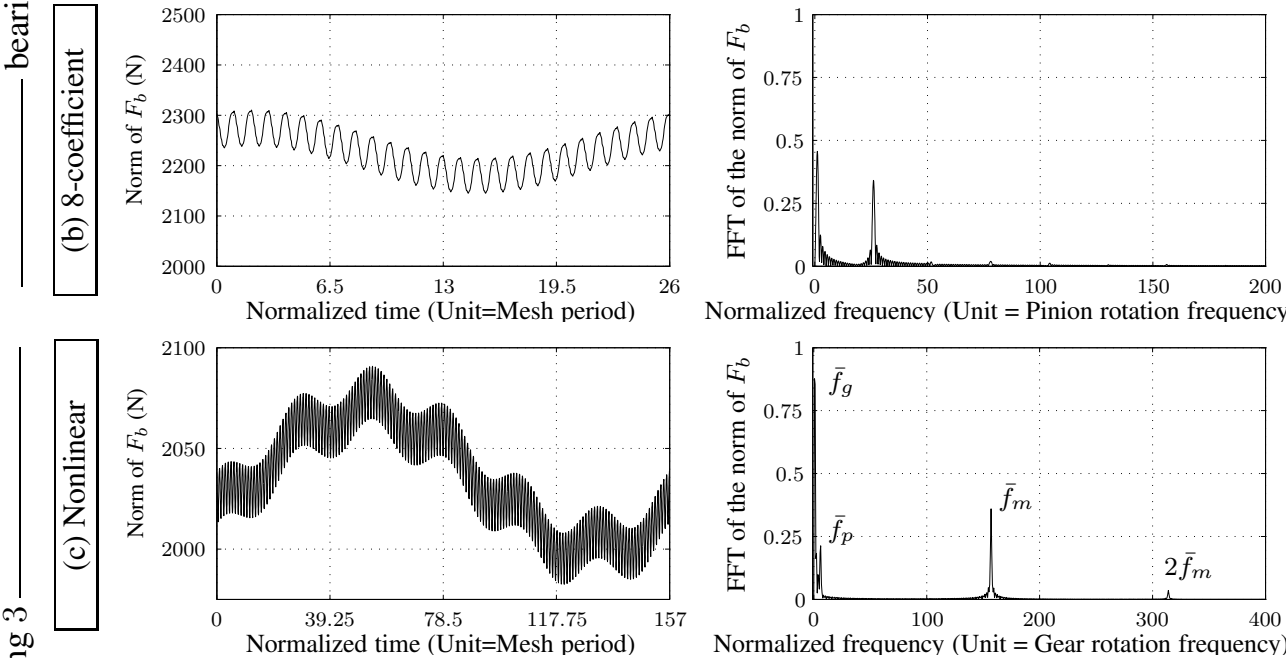

Normalized frequency $($ Unit $=$ Pinion rotation frequency)


Figure 15: Norm and FFT of the hydrodynamic forces in bearings 1 and 3 for a helical gear $\beta=12.5^{\circ}$ at $\omega=325 \mathrm{rad} / \mathrm{s}$. 

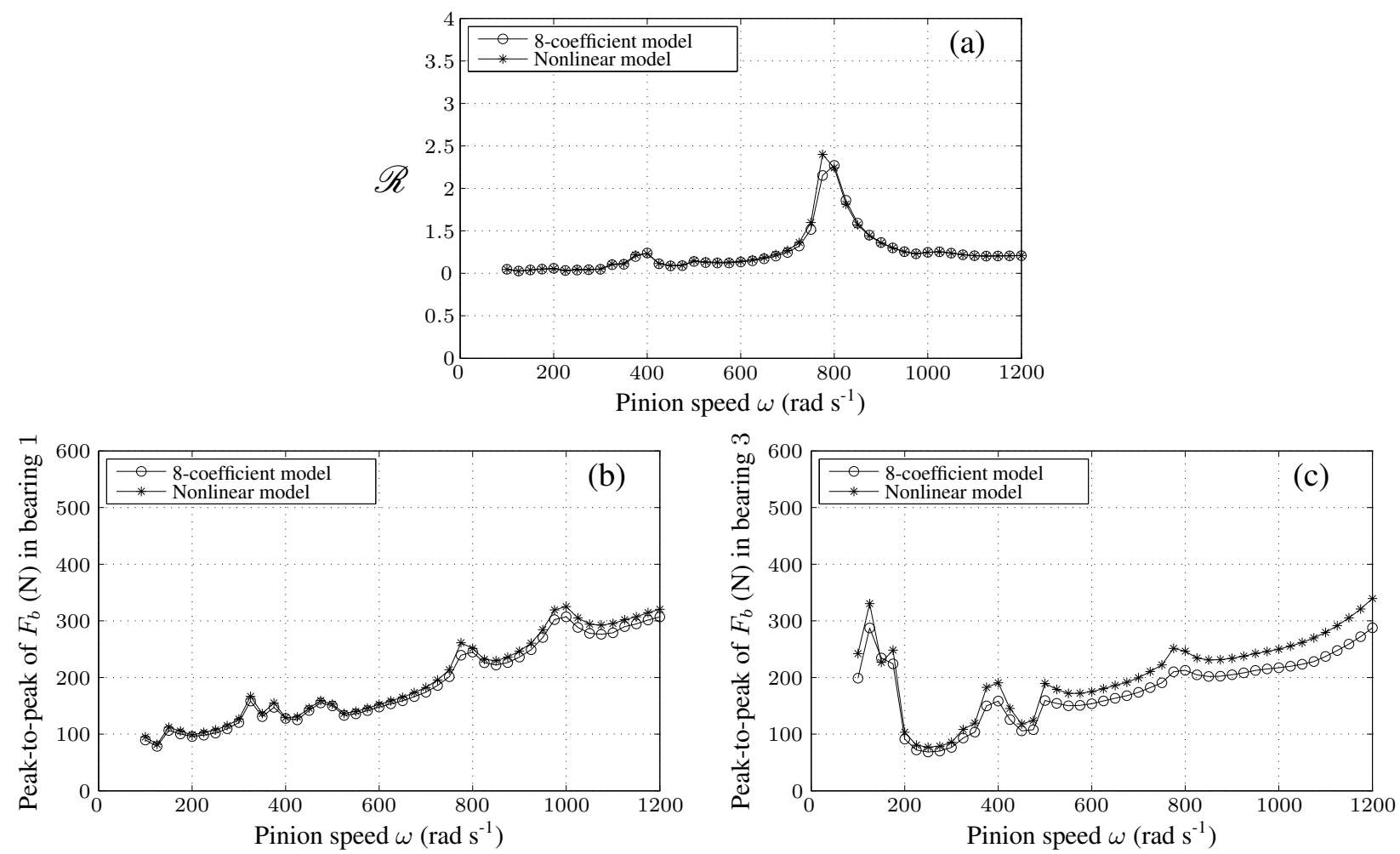

Figure 16: Comparison of the different models for a helical gear $\beta=12.5^{\circ}$ : (a) Dynamic tooth loading $\mathscr{R}$, (b)(c) Peak-to-peak value of the hydrodynamic load $F_{b}$ in bearing 1 and 3 respectively.

$\left\|\mathbf{F}_{\mathbf{b}}\right\|$ are shown in Fig. 16. The nonlinear model, used for all previous computations concerning helical gears, is chosen as reference. The lumped-spring model is unable to predict correct hydrodynamic loads. The linearized 8-coefficient model performs well in bearing 1 but is inaccurate in bearing 3 , whereas it was accurate in both bearings in the case of a spur gear (see Fig. 7). This can be explained with Fig. 17 which provides the transient motion of the output shaft in bearings 3 and 4 computed with the 8-coefficient and the nonlinear models. It can be clearly observed that the center of the shaft moves away from the static position $\mathbf{X}_{\mathbf{0}}$. As a result the assumption of small displacements in the vicinity of $\mathbf{X}_{\mathbf{0}}$ is not verified anymore and the 8-coefficient and nonlinear models give different transient motions and different periodic orbits when steady state is reached. The hydrodynamic forces in bearing 3 during one period of the periodic motion are plotted in Figs. 15(c) and (d) for both models. From these figures it is also observed that the meshing excitations transmitted to the bearings are clearly underestimated when using the 8-coefficient model. These results are confirmed by the evolution of the dynamic tooth load factor $\mathscr{R}$ and the peak-to-peak value of the norm of the hydrodynamic forces in Fig. 16.

\section{Conclusions}

In this paper we have presented a model of gear-shaft-bearing systems that accounts for various time-varying contact nonlinearities and couplings. The proposed numerical procedure combines a very efficient algorithm for computing hydrodynamic forces in finite-length bearings, an accurate semi-analytic distributed gear model, a finite element formulation, and a robust algorithm for nonlinear transient dynamics.

Several representative numerical simulations involving spur as well as helical gears have been presented to demonstrate the good performance of the overall algorithm. The analysis of the dynamic tooth loading, shaft orbits and hydrodynamic fluid forces highlights the coupling between the different components of the gear-shaft-bearing assembly. In particular, it has been shown that mesh excitations appear in the dynamic response although bearing force amplitudes are usually dominated by unbalance. By contrast, dynamic tooth loading sensitivity to once-per-revolution 


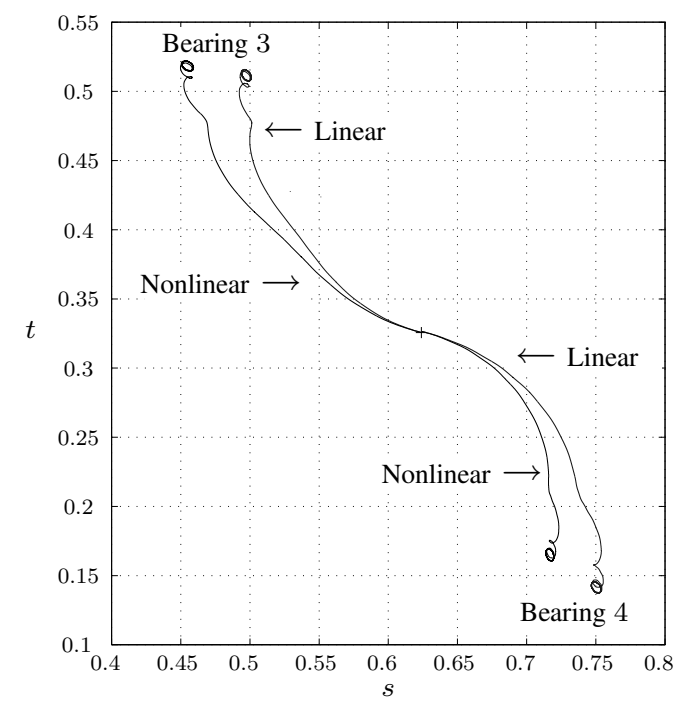

Figure 17: Transient motion in bearings 3 and 4 using linear and nonlinear bearing models for a helical gear $\beta=12.5^{\circ}$ at $\omega=325 \mathrm{rad} / \mathrm{s}$.

excitations seems very limited. Finally, examples have demonstrated that, for accurate predictions of vibration transfer through bearings, bearing nonlinear behavior must be taken into account in the case of large dynamic forces, especially with helical gears.

\section{References}

[1] R. Holmes, The vibration of a rigid shaft in short sleeve bearings, Journal of Mechanical Engineering Science 2 (1960) 337-341.

[2] D. Dowson, A generalized Reynolds equation for film fluid lubrication, International Journal of Mechanical Science 4 (1962) 159-170.

[3] J. W. Lund, The stability of an elastic rotor in journal bearings with flexible damped supports, ASME, Journal of Applied Mechanics (1965) 911-918.

[4] J. F. Booker, Dynamically loaded journal bearings: Mobility method of solution, ASME, Journal of Basic Engineering 4 (1965) 537.

[5] J. Frêne, D. Nicolas, B. Degueurce, D. Berthe, M. Godet, Hydrodynamic lubrication bearings and thrust bearings, Tribology Series, 33, Elsevier Science, Amsterdam, 1997.

[6] G. W. Blankenship, R. Singh, A comparative study of selected mesh force interface dynamic models, in: Proc. 6th ASME Power Transmission and Gearing International Conference, 1992, pp. 137-146.

[7] G. W. Blankenship, R. Singh, A new gear interface dynamic model to predict multi-dimensional force coupling and excitation, Mechanism and Machine Theory 30 (1995) 43-57.

[8] R. W. Gregory, S. L. Harris, R. G. Munro, Dynamic behaviour of spur gears, Proceedings of the Institution of Mechanical Engineers, Vol. 178, 1963, pp. 207-226.

[9] M. Ajmi, P. Velex, A model for simulating the quasi-static and dynamic behaviour of solid wide-faced spur and helical gears, Mechanism and Machine Theory 40 (2005) 173-190.

[10] R. W. Munro, The dynamic behaviour of spur gears, Ph.D. thesis, Cambridge University (1962).

[11] H. N. Özgüven, D. R. Houser, Dynamic analysis of high speed gears by using static loaded transmission error, Journal of Sound and Vibration 125 (1988) 71-83.

[12] P. Velex, M. Maatar, A mathematical model for analysing the influence of the shape deviations and mounting errors on gear dynamics, Journal of Sound and Vibration 191 (5) (1996) 629-660.

[13] A. Kahraman, R. Singh, Non-linear dynamics of a spur gear pair, Journal of Sound and Vibration 142 (1) (1990) 49-75.

[14] A. Kahraman, G. W. Blankenship, Experiments on non-linear dynamic behavior of an oscillator with clearance and periodically time-varying parameters, Journal of Applied Mechanics 64 (1997) 217-226.

[15] R. G. Parker, S. M. Vijayakar, T. Imajo, Non-linear dynamic response of a spur gear pair: modelling and experimental comparisons, Journal of Sound and Vibration 237 (3) (2000) 435-455.

[16] H. N. Özgüven, D. R. Houser, Mathematical models used in gear dynamics - a review, Journal of Sound and Vibration 121 (1988) $383-411$.

[17] J. Wang, R. Li, X. Peng, Survey of nonlinear vibration of gear transmission systems, Applied Mechanics Reviews 56 (3) (2003) $309-329$.

[18] S. V. Neriya, R. B. Bhat, T. S. Sankar, Coupled torsional-flexural vibration of a geared shaft system using finite element analysis, Shock and Vibration Bulletin 55 (1985) 13-25.

[19] A. Kahraman, H. Özgüven, D. Houser, J. Zakrajsek, Dynamic analysis of geared rotors by finite elements, ASME, Journal of Mechanical Design 114 (3) (1992) 507-514.

[20] F. K. Choy, Y. F. Ruan, R. K. Tu, J. J. Zakrajsek, D. P. Townsend, Modal analysis of multistage gear systems coupled with gearbox vibrations, ASME, Journal of Mechanical Design 114 (3) (1992) 486-497. 
[21] H. N. Özgüven, A non-linear mathematical model for dynamic analysis of spur gears including shaft and bearing dynamics, Journal of Sound and Vibration 145 (2) (1991) 239-260.

[22] A. Kahraman, R. Singh, Interactions between time-varying mesh stiffness and clearance non-linearities in a geared system, Journal of Sound and Vibration 146 (1) (1991) 135-156.

[23] S. Baud, P. Velex, Static and dynamic tooth loading in spur and helical geared systems. experiments and code validation, ASME, Journal of Mechanical Design 124 (2002) 334-346.

[24] R. Maliha, C. U. Doğruer, H. N. Özgüven, Nonlinear dynamic modeling of gear-shaft-disk-bearing systems using finite elements and describing functions, ASME, Journal of Mechanical Design 126 (3) (2004) 534-541.

[25] B. Kishor, S. K. Gupta, On the dynamic analysis of a rigid rotor-gear pair-hydrodynamic bearing system, Journal of Vibration, Acoustics, Stress, and Reliability in Design 111 (3) (1989) 234-240.

[26] C.-S. Chen, S. Natsiavas, H. D. Nelson, Coupled lateral-torsional vibration of a gear-pair system supported by a squeeze film damper, Journal of Vibration and Acoustics 120 (4) (1998) 860-867.

[27] S. Theodossiades, S. Natsiavas, On geared rotordynamic systems with oil journal bearings, Journal of Sound and Vibration 243 (4) (2001) 721-745.

[28] S. Baguet, P. Velex, Influence of the nonlinear dynamic behavior of journal bearings on gear-bearing assemblies, in: Proc. ASME Power Transmission and Gearing International Conference, Long Beach, Vol. 5, 2005, pp. 735-745.

[29] C. Weber, K. Banaschek, Formänderung und Profilrücknahme bei gerad- und schrägverzahnten Rädern Schriftenreihe Antriebstechnik, Schriftenreihe Antriebstechnik, Heft 11, F. Vieweg und Sohn, Braunschweig, Germany, 1953.

[30] T. Zheng, Z. Xiao, Z. Wang, An efficient algorithm for fluid force and its jacobian matrix in journal bearing, ASME Journal of tribology 128 (2006) 291-295.

[31] P. Klit, J. W. Lund, Calculation of the dynamic coefficients of a journal bearing, using a variational approach, ASME Journal of tribology 108 (3) (1986) 421-425.

[32] C. Venner, A. Lubrecht, Multilevel methods in lubrication, Tribology series 37, Elsevier, 2001. 